\title{
CONSTRUCCÃO DE UM AQUECEDOR SOLAR DE ÁGUA SUSTENTÁVEL NA AMAZỐNIA: USANDO A METODOLOGIA PBL PARA INTERAÇÃO ENTRE CURSOS DE ENGENHARIA E ESCOLA DE ENSINO MÉDIO
}

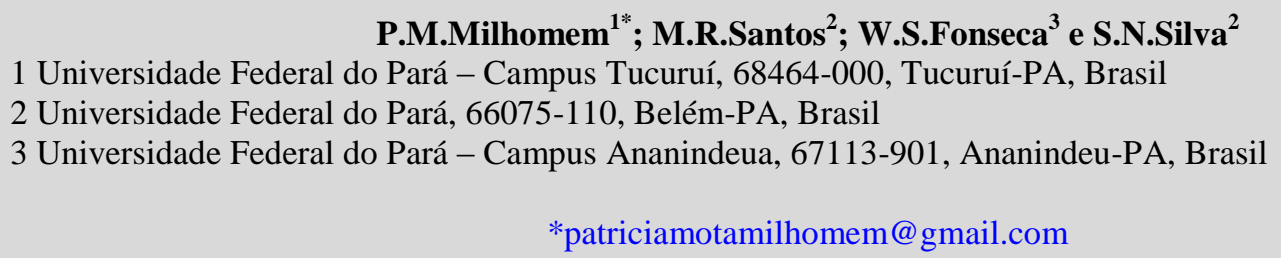

\section{RESUMO}

Em todo o país está sendo amplamente difundida a utilização de fontes de energia renováveis, um dos exemplos claros disso é a obtenção de energia através dos raios solares, como também, o recente avanço na implantação de aerogeradores na região Sul e Nordeste. Com o objetivo de incentivar os alunos do ensino médio em se empenhar no estudo das ciências aplicadas e no desenvolvimento de pesquisa interligada com a eficiência energética, o Programa de Extensão Laboratório de Engenhocas, da Universidade Federal do Pará Campus de Tucuruí, aprovou projetos no CNPq (Conselho Nacional de Desenvolvimento Científico e Tecnológico) com o intuito de inserir nas escolas estaduais de ensino médio do município a metodologia PBL (Project Based Learning), visando ensinar o aluno a aprender, ser proativo e despertar o interesse na área das ciências aplicadas. Dessa forma, os alunos buscaram desenvolver atividades que contribuíssem para minimizar os problemas da sociedade, com isso, construíram e implantaram um Aquecedor Solar de Baixo Custo em uma residência unifamiliar de Tucuruí onde foi possível analisar sua viabilidade e eficiência energética.

\section{CONSTRUCTION OF A SOLAR WATER HEATER SUSTAINABLE IN THE AMAZON: USING THE METHODOLOGY PBL FOR INTERACTION BETWEEN ENGINEERING COURSES AND HIGH SCHOOLS}

\begin{abstract}
Across the country is being widely spread the use of energy renewable, one of the clearest examples of this is to obtain energy by the sun's rays, as well as the latest advances in wind turbine deployment in the South and Northeast. Thus, in order to encourage high school students to engage in the study of science and research development intertwined with energy efficiency. The Laboratório de Engenhocas (hereafter, translated: Gadget Lab) extension program of the Federal University of Pará (UFPA/CAMTUC), approved projects CNPq (National Council for Scientific and Technological Development)
\end{abstract}

in order to insert into in state high schools of the municipality the methodology PBL (Project Based Learning) in order teach the students to learn, be proactive and spark interest in the field of applied sciences. Thus, students sought to develop activities that contribute to minimize the problems of society, thus, was the built and implemented a Low Cost Solar Heater in a single family residence Tucuruí where it was possible to analyze its feasibility and efficiency.

KEYWORDS: Solar Heater, Sustainability, Engineering, High School, PBL. 


\section{INTRODUÇÃ̃O}

Um dos grandes desafios para a humanidade neste século é o de fazer a transição para um futuro de energia sustentável, com isso, a nível mundial segue como ponto de pauta a utilização de fontes de energia renováveis, segundo a Associação Brasileira de Energia Eólica (ABEEÓLICA, s.d), o investimento mundial em energias renováveis, impulsionadas pelas solar e eólica, cresceu 17\% no ano de 2014 com relação a 2013, chegando aos US\$ 270 bilhões. Dessa forma, afirma que as energias eólica, solar, geotérmica, marinha, de biomassa e de pequenas centrais hidrelétricas contribuíram com 9,1\% da geração mundial de eletricidade no ano 2014, contra 8,5\% em 2013.

Os desafios da energia sustentável é uma tarefa tão desalentadora quanto complexa, a dinâmica que impele as tendências atuais de energia é enorme e será difícil contê-la no contexto dos altos níveis de consumo existente em muitos países industrializados; do crescimento contínuo da população; da rápida industrialização em países em desenvolvimento; da infraestrutura energética bem estabelecida, capital-intensiva e de longo prazo; e crescente demanda por serviços e amenidades relacionados à energia em todo o mundo (Copyright Inter Academy Council, 2007).

No Brasil, apesar do grande avanço no setor da geração de energias renováveis, principalmente, através da implantação de aerogerados, basicamente, no Nordeste e no Sul o cenário é ainda muito desafiador (Melo, 2014).

De acordo com o Programa Nacional de Conservação de Energia Elétrica - PROCEL (2010), 95\% da energia brasileira é gerada através de usinas hidroelétricas e a partir do momento em que a sociedade decide produzir energia elétrica de forma mais eficiente e, sustentável, usinas, linhas de transmissão e redes de distribuição que teriam de ser construídas para atender o crescimento da demanda, poderiam ser evitadas, ou postergadas. Como também, áreas de vegetação deixariam de ser alagadas e desmatadas, realidade corrente no Norte do país.

Preocupados em levar para a sociedade a importância da produção de energias limpas, uma vez que todos direta ou indiretamente podem contribuir para o país atingir resultados sustentáveis. Foi proposto junto ao Programa de Extensão Laboratório de Engenhocas da Universidade Federal do Pará - Campus Tucuruí (UFPA/CAMTUC) e a Escola Estadual de Ensino Médio Rui Barbosa uma alternativa de divulgar a importância do uso de energias sustentáveis no município de Tucuruí. Inicialmente, realizou-se uma seleção entre os alunos da escola para integrarem ao Programa e participassem diretamente dos projetos aprovados no CNPq sendo eles: "Feira de Ciências de Tucuruí: Inovação Tecnológica e Sustentabilidade"; e "Implantação do Laboratório de Engenhocas em escolas de Ensino Médio", esse último aprovado na chamada CNPq/VALE S.A N 05/2012 FORMA-ENGENHARIA. Através desses projetos e da utilização da metodologia PBL os alunos desenvolveram várias atividades relacionadas à Ciência e Tecnologia (Milhomem, et al., 2013).

O PBL (Project Based Learning) é uma metodologia voltada ao aprendizado, que proporcionam ao aluno aquisição de conhecimento crítico, proficiência em solução de problemas, estratégias de aprendizagem e habilidades de participação. Uma vez que a mesma exige a proatividade do aluno, para que o mesmo procure o conhecimento nos diversos meios de difusão disponíveis encontre a solução para problemas reais a partir do trabalho em equipe, da discussão e da análise crítica (Campos et al., 2011).

Dessa forma, o presente trabalho enfatiza a importância de confeccionar um Aquecedor Solar de Baixo Custo (ASBC) por ser um dispositivo que funciona a partir da incidência de raios solares possibilitando assim uma economia de energia elétrica nas residências, seu material de construção é composto principalmente por garrafas pet e embalagens Longa Vida, materiais que na sua maioria são descartados poluindo o meio ambiente.

Sistemas de aquecimento de água por energia solar podem ser instalados em diversos tipos de estruturas, como: edificações multi-familiares, prédios comerciais e residências unifamiliares, 
desde que possa atender a demanda de consumo e possuir eficiência na conversão da energia solar em energia térmica.

O projeto contribuiu significativamente para a ampliação dos conhecimentos dos alunos envolvidos, uma vez que as informações teóricas acumuladas no decorrer das aulas passaram a ser colocadas em práticas e assimiladas com os fenômenos físicos ocorridos para o bom funcionamento do ABSC, fixando e facilitando o aprendizado das disciplinas de exatas, além de estimulá-los a procurar conhecimentos e formação nessas áreas.

\section{MONTAGEM DO ASBC}

Inicialmente realizou-se um estudo de viabilidade econômica do uso da energia solar a partir da construção de um ASBC em uma residência unifamiliar. Além de promover um debate na Escola Estadual de Ensino Médio Rui Barbosa sobre fontes renováveis de energia despertando na sociedade Tucuruiense a importância da reutilização dos materiais.

Em seguida, analisou-se o local e organizou a equipe de apoio, a maioria alunos da Escola Estadual de Ensino Médio Rui Barbosa e bolsistas de Iniciação Científica Júnior e bolsistas de Iniciação Tecnológica e Industrial do CNPq, que participavam do Projeto Feira de Ciências e o Projeto Laboratório de Engenhocas no Ensino Médio, respectivamente, orientado pelo professor coordenador do Programa de Extensão Laboratório de Engenhocas da (UFPA/CAMTUC) e coorientada por uma bolsista estudante de engenharia participante do programa.

Após a definição da equipe, o terceiro passo foi à revisão bibliográfica sobre energia solar e obtenção do material didático para auxiliar na confecção do ASBC (Alano, 2008). Nesse período, também foi realizado todo o quantitativo e arrecadação do material que seria utilizado, definindo que seriam utilizadas 300 (trezentas) garrafas PET e 300 embalagens Longa Vida, observados na Figura 1 e Figura 2, ou seja, 50 embalagens PET e Longa Vida pós-consumo por pessoa da residência.

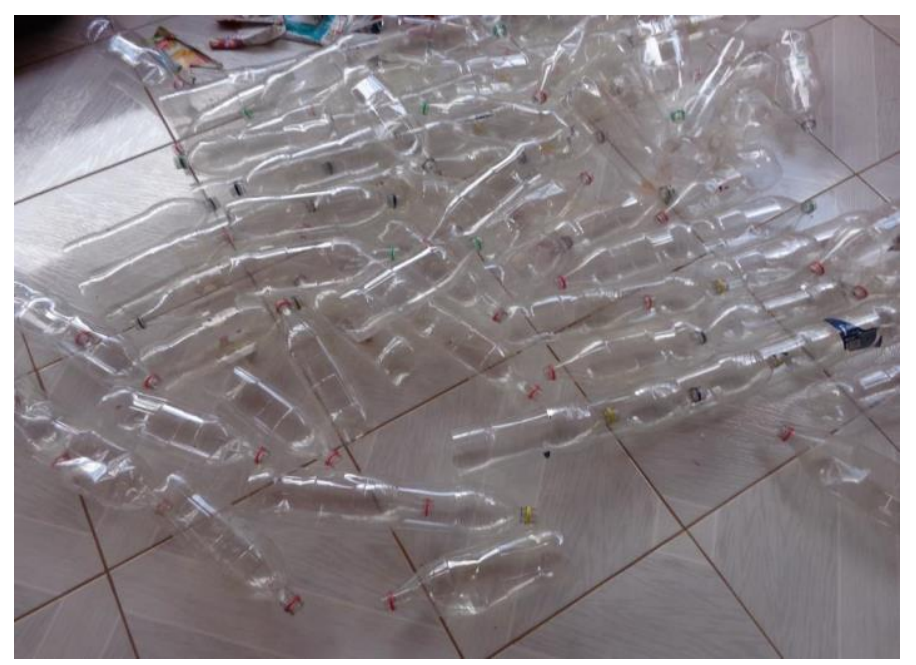

Figura 1 - Garrafas PET Recolhidas

Fonte: Os autores (2013). 


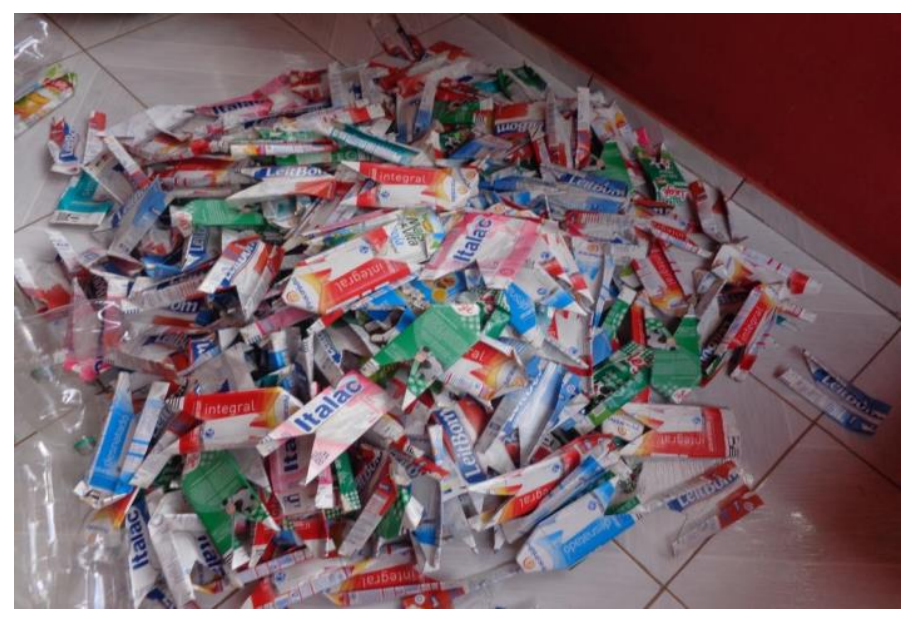

Figura 2 - Caixas de Leite Tetra Pak

Fonte: Os autores.

Depois de adquirida as embalagens, as mesmas foram lavadas, cortadas e pintadas com tinta óleo de cor preta, como observado na Figura 3.

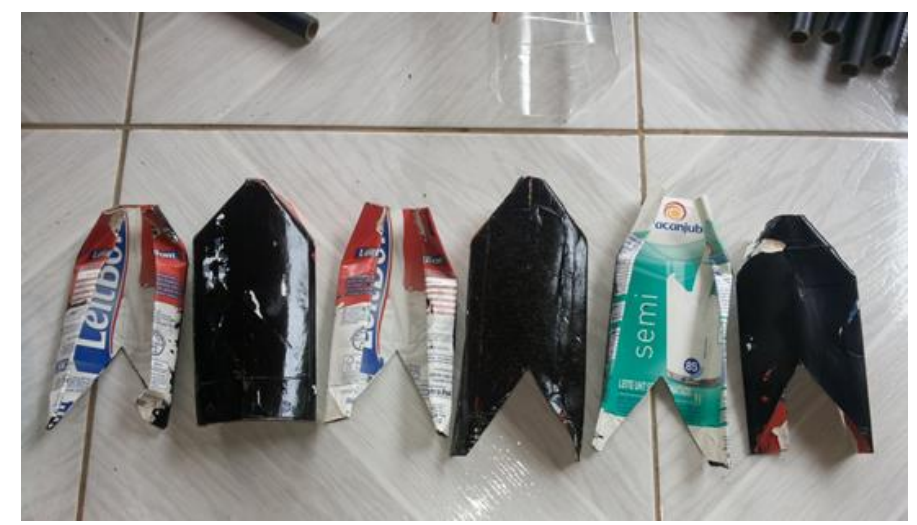

Figura 3 - Corte e Pintura das Caixas Tetra Pak Fonte: Os autores.

A montagem da placa do aquecedor iniciou com a pintura dos canos PVC de 6 metros de comprimento e 20 milímetros de diâmetro com tinta óleo de cor preto fosco, com o intuito de melhorar na absorção dos raios solares. Após estarem secos os canos foram cortados com comprimento de um metro, algumas varas de cano PVC não foram pintadas, apenas cortadas formando assim pequenos "pedaços" de cano com $10 \mathrm{~cm}$ de comprimento, em seguida esses "pedaços" foram encaixados nas conexões de 3 furos de $20 \mathrm{~mm}$ de diâmetro (conhecido como "T"), como mostra a Figura 4. 


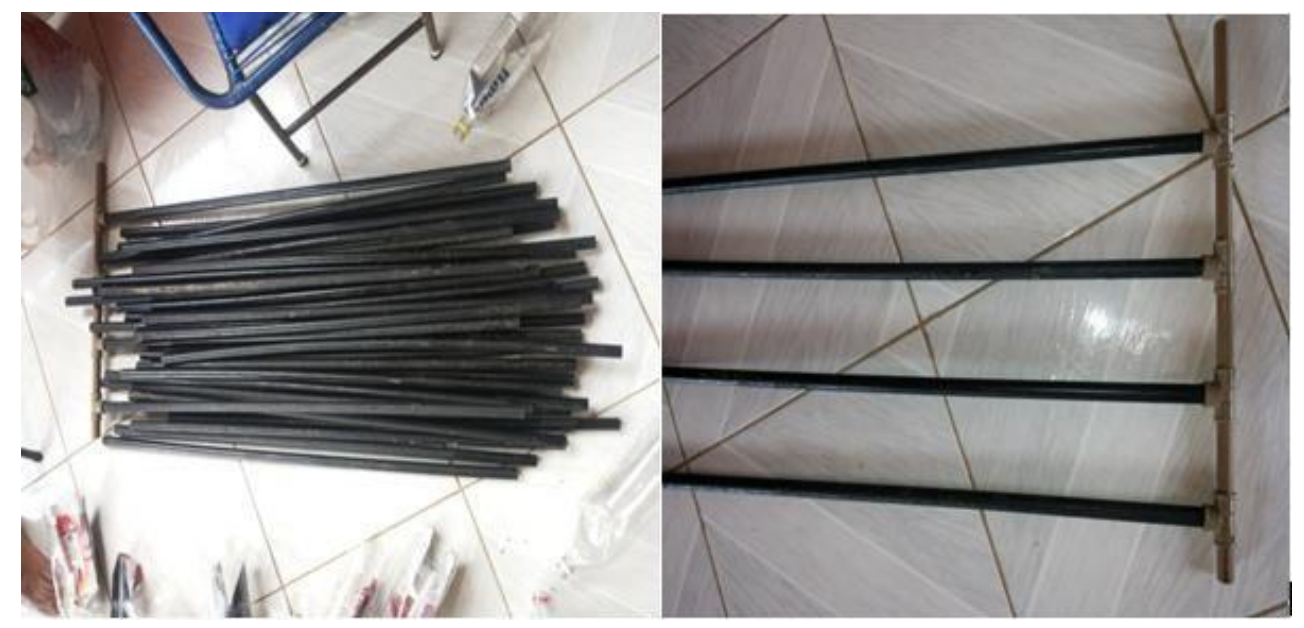

Figura 4 - Canos Pintados de Preto e Conexões T.

Fonte: Os autores.

Após a montagem da placa que resultou em um comprimento de 7,60 m, o próximo passo foi às devidas adaptações e instalações na caixa d'água e no banheiro da residência demonstrado pela Figura 5.

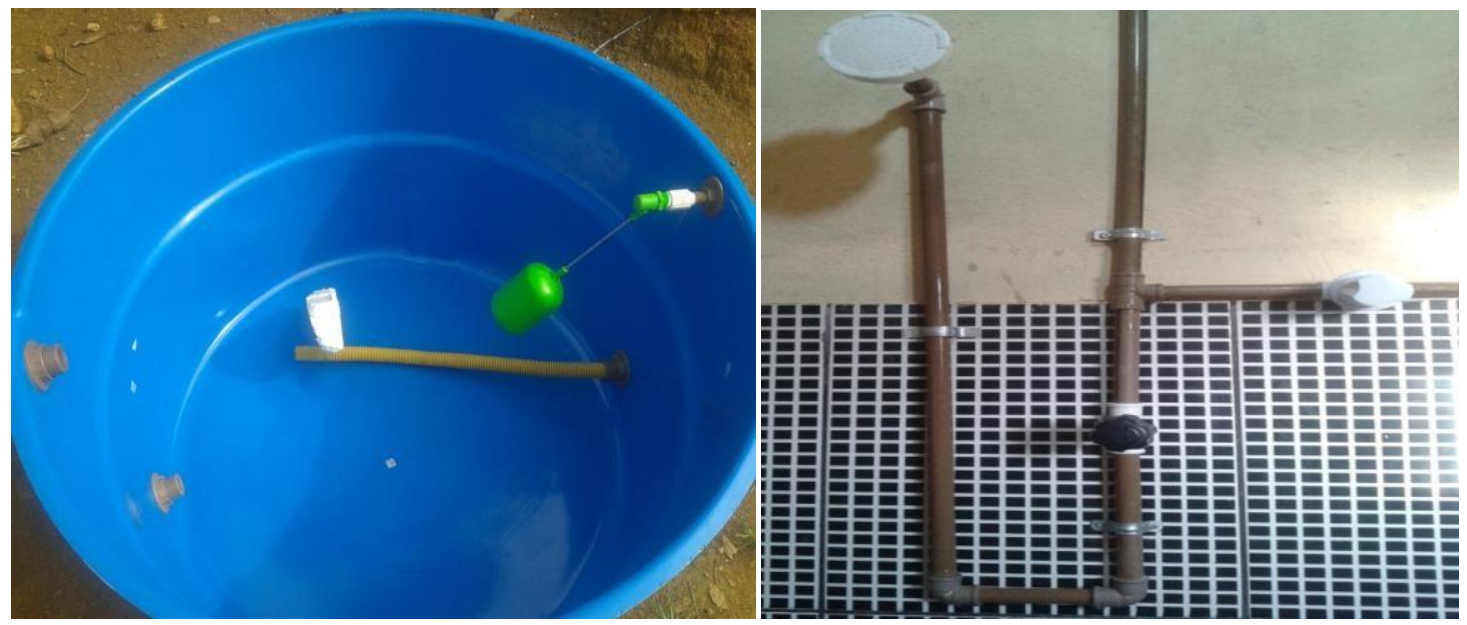

Figura 5 - Instalações na caixa d'água e no banheiro da resid.

Fonte: Os autores. 
Com a finalização da construção do sistema térmico, o coletor solar ficou posicionado com um ângulo de $20^{\circ}$ em relação a caixa de fornecimento de água fria, e a caixa com água aquecida ficaram dispostas como ilustrado na Figura 6.

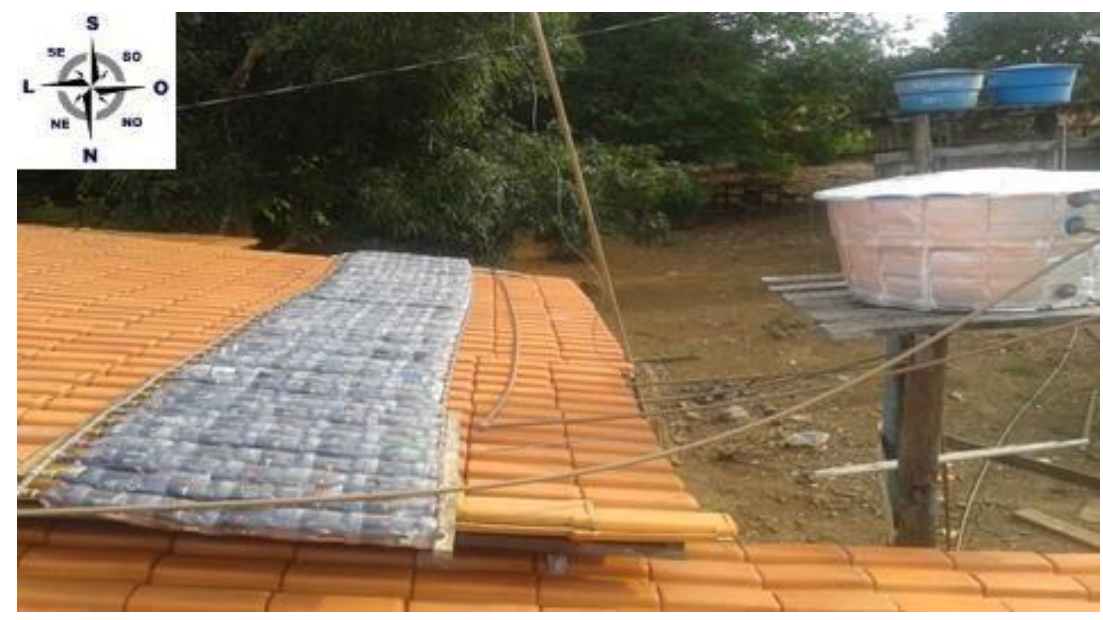

Figura 6 - Sistema Térmico Montado.

Fonte: Os autores.

\section{RESULTADOS E DISCUSSÃO}

Por constituir de materiais reutilizados, o ASBC é um importante meio de prevenção do meio ambiente, pois efetua um processo de reciclagem direta, além de apresentar uma série de vantagens, como: prolongamento da vida útil dos aterros, a redução de impactos ambientais, entre outros. A coleta de materiais recicláveis oportunizou a discussão de cuidados no manuseio do lixo e a sua importância. Além disso, se comparado o custo- benefício entre o aquecedor comercial e o alternativo, é evidente que o alternativo é muito mais vantajoso financeiramente, como detalhado na Tabela 1:

Tabela 1 - Comparação de Preços

\begin{tabular}{|l|c|c|c|}
\hline \multicolumn{1}{|c|}{ Tipo de Aquecedor } & Custo de Implantação & $\begin{array}{c}\text { Custo de } \\
\text { Manutenção Anual }\end{array}$ & Total R\$ \\
\hline Aquecedor Solar de Garrafas PET & 772,73 & 100,00 & 872,73 \\
\hline Aquecedor Solar Industrial & $3.210,00$ & 100,00 & $3.310,00$ \\
\hline
\end{tabular}

O sistema térmico teve seu custo calculado a partir do material gasto na montagem do protótipo. Como há variação de preço dependendo da localidade de compra, vale ressaltar que todos os componentes do sistema foram adquiridos no comércio local.

A partir do levantamento dos valores de aquisição e manutenção cedidos gentilmente pela empresa SOLETROL de seu aquecedor solar industrial, e somados os custos na construção do sistema de aquecimento ASBC, comprovou-se que o aquecedor alternativo é uma aquisição viável economicamente, pois, na comparação com o valor do sistema de aquecimento industrial, há uma grande diferença entre os custos de implantação.

Além de verificar o menor custo do sistema, outro objetivo foi comprovar sua eficiência, através do levantamento das características apresentadas pela água, levando-se em consideração a temperatura máxima atingida e seu tempo de aquecimento. $\mathrm{O}$ termômetro utilizado foi construído a 
partir do Arduíno, uma plataforma de prototipagem eletrônica, seu funcionamento ocorre através de um termistor que realiza a conversão da variação de resistência para graus Celsius.

O circuito é alimentado por uma fonte de corrente contínua e o sinal de saída dos sensores de temperatura é conectada a uma entra analógica do micro controlador, através do conversor A/D do micro controlador esse sinal analógico é transformado para sinal digital, tornando o valor medido disponível ao usuário através de um display LCD.

$\mathrm{Na}$ Figura 7 é apresentado o circuito elétrico elaborado, representando o circuito de coleta de temperatura. Nesse circuito foram utilizados dois sensores de temperatura responsáveis pela coleta de dados e um display LCD responsável por permitir a leitura desses dados pelo usuário de uma forma inteligível. Os dispositivos utilizados foram: Dois Termistores NTC 10K, Um Display LCD $16 \times 2$.

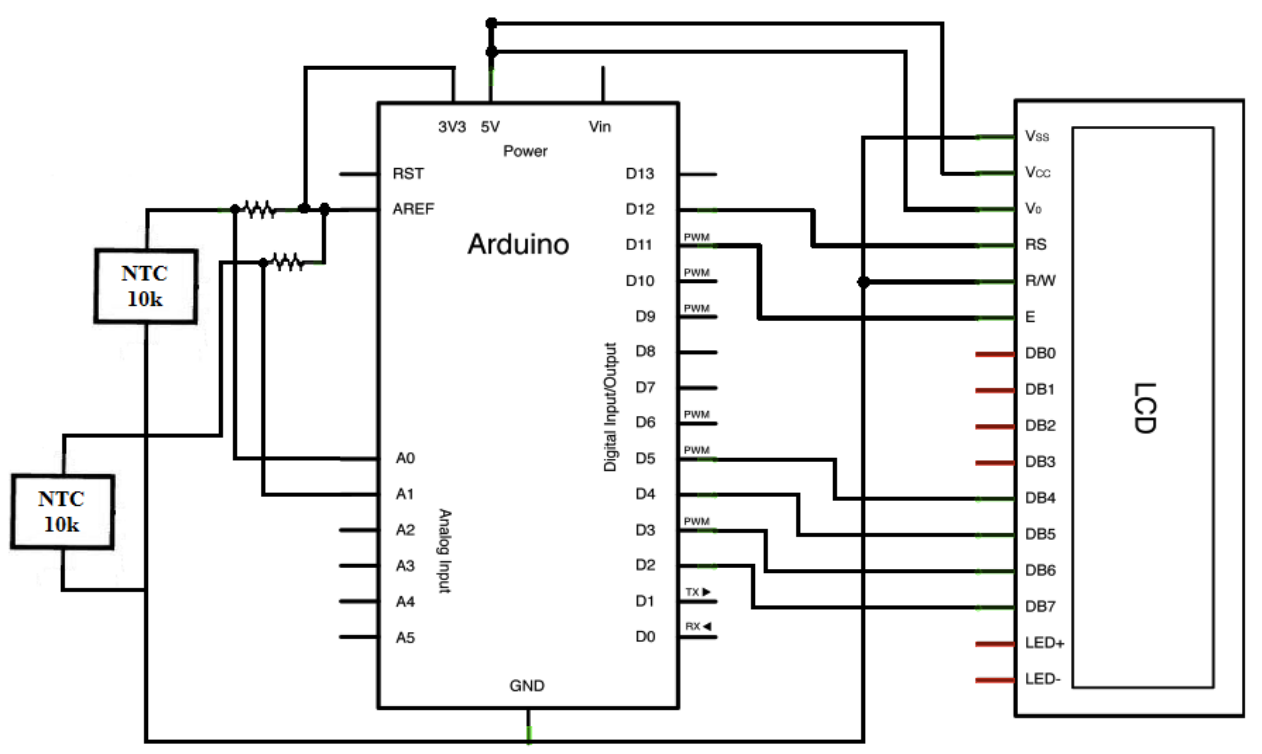

Figura 7 - Circuito Elétrico.

Fonte: Elaborado pelos autores.

Os NTC 10k foram conectados às portas analógicas do arduíno, pois, através delas converte as variações de tensão nas entradas provocadas pela variação de resistência dos sensores em temperatura.

O display LCD 16x2 foi conectado a uma porta digital configurada como saída do micro controlador, nele o usuário poderá ver os dados dos sensores em tempo real, como também, verificar o que aconteceu no sistema estudado em um determinado período de tempo. Foi utilizado um notebook para servir como fonte de alimentação para o Arduíno, e esta conexão foi feita através de um cabo USB.

A s medições aconteceram nos dias 24, 25 e 26 de janeiro de 2014, os dados foram coletados no período das $9: 00 \mathrm{~h}$ às $21: 00 \mathrm{~h}$ com intervalo a cada 2:00h, para facilitar o acompanhamento da temperatura, observando assim a variação de temperatura da água no chuveiro da residência. A água estava interligada ao reservatório térmico onde era coletada, o mesmo acontecia com o fluido do reservatório de fornecimento. 
Após as medições serem realizadas foram plotados gráficos para tratar os dados. Na Figura 8 exibiram-se os valores referentes aos três dias de amostragens com a finalidade de analisar melhor as variações ocorridas durante o registro dos resultados.

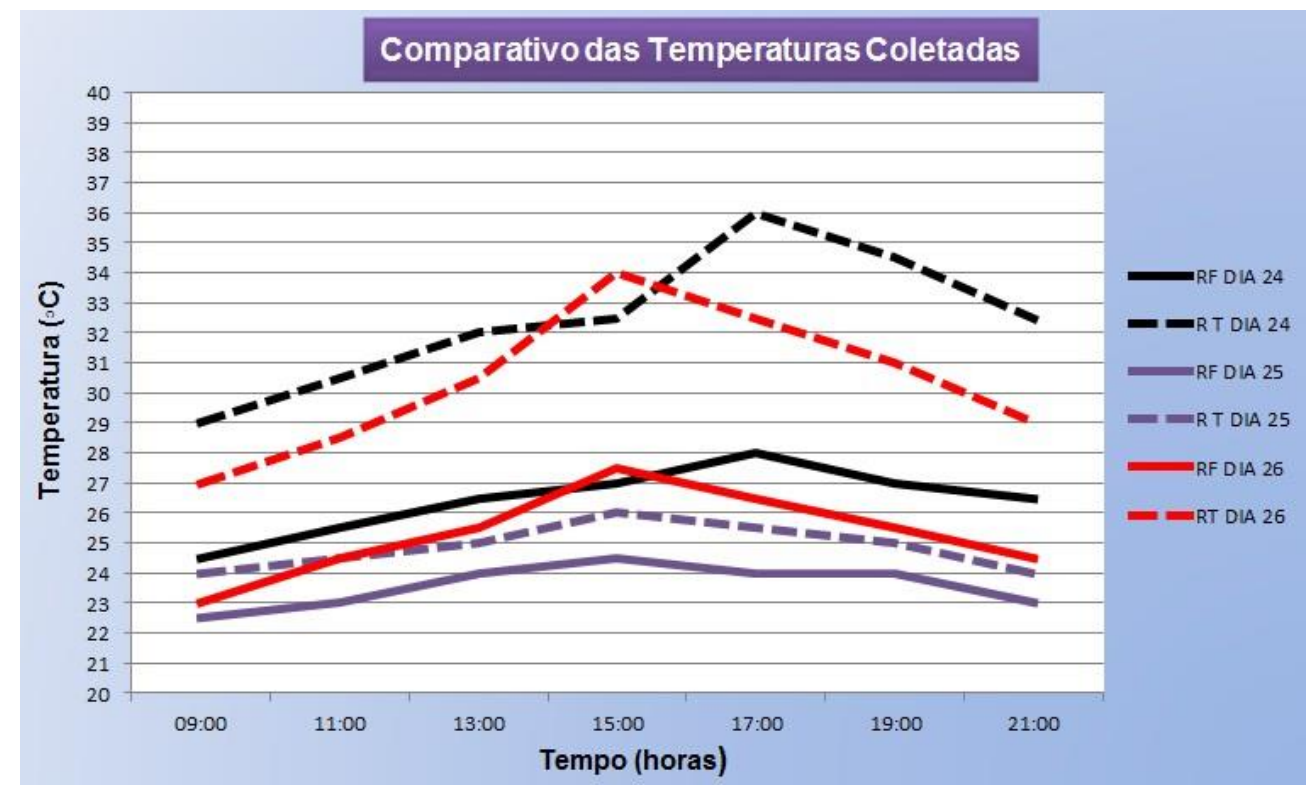

Figura 8 - Amostragens das Temperaturas.

Fonte: Elaborado pelos autores.

É preciso ressaltar que as medições de temperatura ocorreram durante o período de inverno mais rigoroso de Tucuruí (PA), portanto, em alguns momentos o tempo ficou chuvoso e nublado, impossibilitando então uma incidência solar no coletor. Porém os resultados mostraram-se satisfatórios, pois em todas as medições o reservatório térmico apresentou temperatura mais elevada que o reservatório de fornecimento.

Além do resultado da eficiência do Sistema Térmico, outro resultado adquirido foi a contribuição na ampliação dos conhecimentos dos alunos envolvidos, uma vez que as informações teóricas acumuladas no decorrer das aulas, passaram a ser colocadas em práticas e assimiladas com os fenômenos físicos para o bom funcionamento do ASBC. Dessa forma, fixando e facilitando o aprendizado das disciplinas de exatas, além de estimula-los a procurar conhecimentos e formação nessas áreas. $\mathrm{O}$ aquecedor solar permitiu os alunos participarem da maior Feira Brasileira de Ciência e Engenharia (FEBRACE 12).

\section{CONCLUSÃO}

Uma das grandes deficiências da docência no ensino médio é a falta de incentivo à pesquisa e a pouca diversificação das metodologias de ensino que dificultam o aprendizado e a futuras decisões profissionais. Assim, a aplicação da metodologia PBL nas escolas de ensino médio de Tucuruí ampliou as formas de ensino, pois, com a construção do Aquecedor Solar de Baixo Custo, os alunos puderam colocar em prática os assuntos vistos em sala de aula, além de mostrarem inovação, criatividade, desenvolvimento da proatividade e a experiência do trabalho em equipe.

O projeto fortaleceu o vínculo entre a Escola Estadual de Ensino Médio Rui Barbosa, a Universidade Federal do Pará e a sociedade, de modo que ambas saíram beneficiadas desse processo, pois, permitirá a aplicação do conhecimento dos alunos envolvidos em prol do desenvolvimento da comunidade tucuruiense, dessa forma, contribuindo diretamente nas atividades 
sociais. Deseja-se contribuir nas políticas que promovam e valorizem o bem estar das pessoas e do meio ambiente.

É esperado que esse projeto possa ser um atrativo para os estudantes escolherem cursar alguma graduação em engenharia, haja vista, que nele desenvolvem as principais características de um engenheiro. Por isso, foi feita uma parceria entre o Laboratório de Engenhocas e as Escolas de Ensino Médio de Tucuruí no "Projeto Feira de Ciência", que se tornou o principal meio de identificar talentos, através da exposição de trabalhos científicos, sendo um deles a apresentação do Aquecedor Solar de Baixo Custo. Acredita-se que com o andamento do projeto, possa conseguir tornar o ensino de ciências nas escolas mais didático contribuindo para o aprendizado do aluno e atraindo-os para as universidades.

\section{AGRADECIMENTOS}

O grupo envolvido neste trabalho agradece a colaboração entre a UFPA e Empresa Eletrobrás/Eletronorte pelo constante apoio aos projetos do Campus Tucuruí. Agradecimentos também a Vale e ao CNPq pela colaboração no projeto "Laboratório de Engenhocas no Ensino Médio".

\section{REFERENCIAS}

ABEEÓLICA. Um ano de "Avanços Chamativos" para a energia renovável. DISPONÍVEL EM < HTTP://WWW.ENVOLVERDE.COM.BR/AMBIENTE/UM-ANO-DE-AVANCOS-CHAMATIVOS-PARA-AENERGIA-RENOVAVEL/>. Acesso em outubro de 2015.

ALANO, J.A. Manual Aquecedor Solar. Disponível em: http://www.planetareciclavel.com.br/desperdicio_zero/Kit_res_17_solar.pdf> Acesso em: 29 de maio de 2013.

CAMPOS, L.C.; DIRANI, E.A.T.; MANRIQUE, A.L. Educação em Engenharia. Novas abordagens. São Paulo: EDUC, 2011.

COPYRIGHT INTER ACADEMY COUNCIL. Um futuro com energia sustentável: Iluminando o caminho. 2007, Disponível em < http://www.fapesp.br/publicacoes/energia.pdf>. Acesso em outubro de 2015.

MELO, E. Investimentos em Energia Eólica no Brasil: Aspectos de Inserção, Tecnologia e Competitividade. Revista Concreto, p.136-139, 2014.

MILHOMEM, P.M.; BEZERRA, W.M.; SOUZA, D.A.; FONSECA, W.S.; BARROS, F.B. Aplicando a metodologia PBL na região Amazônica para incentivo ao Estudo em Engenharia. International Symposium on Project Approaches in Engineering Education - PAEE, 2013.

PROCEL (site) - Portal da Eletrobrás Eletronorte. Disponível em <http://www.eletrobras.com/elb/procel/main.asp> Acesso em setembro de 2013.

SOLETROL (site). Aquecedores Solares de Água. Disponível: <http://www.soletrol.com.br/noticias/agua_e_sol/12/pg02.php> Acesso em setembro de 2013.

TAVARES, J.R.; SANTOS, M.R.; SILVA, R.R.; FONSECA, W.S.; MILHOMEM, P.M. Implantação de um Aquecedor Solar de Baixo Custo na Amazônia. Feira Brasileira de Ciências e Engenharia - FEBRACE 2014. 